called in. If then the machine stops on account of an error, the sequence of code letters printed will help the programmer to localize the error. Later, when the programme has been proved to work satisfactorily, the printing of code letters can be cut out. In a similar way, it is a good idea to begin by including orders in the programme which will print out extra numerical information that can be used for checking purposes. These orders can also be removed when the programme has been shown to work correctly. For more detailed checking there are a number of sub-routines in the library which, when attached to a programme, cause the machine to print (in addition to, or instead of, the numbers specified in the programme) some detailed information which can be analysed afterwards. Thus, the machine may print a letter specifying the type of each order (for example, $A$ for add, $S$ for subtract, etc.) as it is executed; alternatively, the number in the accumulator register may be printed each time it is cleared.

It frequently saves time in the long run if those sub-routines which have been constructed specially for the problem are tested on the machine before being incorporated in the full programme. The subroutines from the library, of course, are known to be free from error, and this fact alone would make the use of a library highly desirable, quite apart from other advantages.

Members of the summer school were shown various examples of programmes prepared for the EDSAC, including one for obtaining solutions of Emden's differential equation which occurs in astrophysics. The EDSAC has also been applied to problems arising in geophysics, wave mechanics, statistics, electron opties and electrical engineering.

\section{V. WILKES}

\section{SPECIAL LIBRARIES AND INFORMATION SERVICES}

$\mathrm{T}$

HE twenty-fifth annual conference of Aslib, held at the University of Bristol during September 22-25, marked the beginning of the second quartercentury of service of the Association of Special Libraries and Information Bureaux, and was attended by two hundred and thirty delegates representing a wide variety of interests and studies, scientific and humane. The conference was welcomed by the vicechancellor of the University, Sir Philip Morris, at a clinner and reception on the night of September 22.

At the opening session on the morning of September 23 the president of the Association, Dr. Percy Dunsheath, made a short speech in which he described Aslib as an "invisible investment" paying to the nation dividends both tangible and generous, since it is a society of special libraries-"places where the progress of science and specialized knowlfdge are fostered and furthered at every step". The usual presidential address was replaced by one by the director, Mr. Leslie Wilson, who paid a warm tribute both to the voluntary effort which has built up the Association in the past and to the generous support received for some years through the Department of Scientific and Industrial Research and now greatly increased. While welcoming the present trend in national life towards a partnership between voluntary effort and State support, he emphasized the obligation on recipients of such support to think in terms of the national and not merely the professional need. The primary duty of Aslib at the present time is to those, particularly in industry, who are called upon to be the leaders in national recovery. The main sinew of their effort is industrial research ; it is Aslib's concern that more special libraries and information bureaux should be set up in industry to supply vital scientific and technical information to research departments. The Association hopes to establish more local branches and a number of groups representing the interests of particular professions or trades, expanding by these means not only its membership but also one of its most valuable services - the provision of facilities for the cross-fertilization of ideas. Aslib is well represented on the Nicholson Committee, the successor of the King Panel on Technical Information Services, and is responsible for representing Great Britain (the director hoped with increasing energy) in the field of international documentation. There is still an enormous field for research in special library methods, and Mr. Wilson said that he hopes before long to set up a research committee to carry on this work and publish its results. He could not envisage a single organisation serving effectively both the technical and the professional interests of librarianship-it might be that the latter should rest more particularly on the Library Association-but he felt sure that the fundamental activity of Aslib must in the long run consist of research into the techniques of special librarianship and information work.

On the afternoon of September 23, Mr. F. L. Kent, librarian of the University of Bristol, pressented a paper on the library resources of Bristol and the south-west of England. It is hoped that similar surveys of other regions will enable a general view to be arrived at of the resources of Great Britain as a whole, particularly in special and technical libraries which might be willing to co-operate in the national inter-library lending service. The paper was followed. by a comprehensive programme of visits to libraries, including the University Library (general and medical libraries, engineering division, and botany and zoology departments), the City Library and the South-Western Regional Library Bureau, and the libraries of the Bristol Aeroplane Co. and the National Smelting Co.-most delegates being able to visit at least two of these. In addition, arrangements were made for individual delegates to see the libraries of the University of Bristol Institute of Education, Southmead Hospital and Messrs. W. D. and H. O. Wills, Ltd.

The third session, on the morning of September 24, consisted of papers by Miss M. Exley and Mr. W. Ashworth on the re-planning and re-organisation of special libraries, the former being concerned mainly with buildings, equipment and administration, and the latter with re-cataloguing and re-classification. At the afternoon meeting, Miss E. Ditmas, former director of Aslib, presented a paper on the literature of special librarianship, containing a select bibliography of three hundred items, copies of which were exhibited in an adjoining room. This paper gave rise to useful discussion on the future publishing programme of Aslib and the possibility of collaboration with the Library Association in this field. The conference concluded with a paper on the Earl of Leicester's Library at Holkham Hall by Dr. W. O. Hassall, who, to at least one member of his audience, conveyed once again that sense of the unity underlying all the diversities of librarianship, research and learning which was present throughout the conference.

F. L. KENT 